\title{
A REPRESENTAÇÃO DOCUMENTAL NO CONTEXTO DA ARQUIVOLOGIA: PERPECTIVAS RECENTES
}

\author{
ARCHIVAL REPRESENTATION: RECENT \\ PERSPECTIVES
}

Thiago Henrique Bragato Barros a

\begin{abstract}
RESUMO
Introdução: Os processos de representação fazem parte do cotidiano dos arquivos, bibliotecas e museus. Neste sentido, busca-se no universo dos arquivos apropriar-se das discussões relacionadas a representação e organização da informação e do conhecimento. Objetivos: Neste artigo discorre-se a respeito do percurso do conceito de representação primeiro no contexto da organização depois no contexto da arquivologia, com a intenção de sistematizar as várias facetas do conceito de representação e aproximá-los dos processos arquivísticos. Metodologia: O trabalho foi desenvolvido analisado a literatura de ambas as áreas ao redor do conceito de representação. Resultados: Como trata-se de um estudo teórico que discute e sistematiza a literatura da área, fica claro a presença de um conceito de representação na arquivologia, ainda que configurado em uma realidade distinta da ideia presente na Organização do Conhecimento. Conclusões: No sentido de busca-se trabalhar com as convergências entre esses campos e apresentar possiblidades de relacionamento aprimorando a construção de instrumentos de representação no contexto dos arquivos na atualidade.
\end{abstract}

Descritores: Representação. Arquivologia. Organização do conhecimento.

\section{INTRODUÇÃO}

A representação na realidade dos arquivos sempre, ainda que presente na literatura internacional da área, foi um tema pouco explorado, quando levando em consideração estudos sistemáticos e programáticos a frequência da discussão é ainda menor. Destacamos aqui os estudos de Yakel (2003; 2011), Henttonen e Kettunen (2011), Henttonen ( 2012; 2015), Packalén e Henttonen

\footnotetext{
a Doutor em Ciência da Informação pela Universidade Estadual Paulista Júlio de Mesquita Filho (UNESP). Docente do Departamento de Ciência da Informação e dos Programas de PósGraduação em Ciência da Informação da Universidade Federal do Rio Grande do Sul (UFRGS). Email: bragato.barros@ufrgs.br
} 
(2016), Barros e Moraes (2012; 2013), Barros (2016), Barros e Gomes (2018), Barros e Sousa (2019a, 2019b), Guimarães e Tognoli (2015) e Tognoli, Guimarães e Rodrigues (2019), Alencar e Cervantes (2019a, 2019b). Os estudos descritos em maior ou menor grau trabalharam aspetos da representação, organização do conhecimento, classificação, descrição, indexação entre outros.

Assim é possível perceber que são temáticas que tem intensificado em produção e destaque. Por outro lado, a comunidade que trabalha com a temática não é grande o que se percebe, é que existe na maioria dos casos uma vinculação segundaria a representação. Os conceitos que mais se aproximam ainda que não de forma clara, concentram-se fortemente ao redor do trabalho classificatório e descritivo do material de arquivos, que são por si só processos que se relacionam com a gestão, preservação e acesso aos documentos arquivísticos.

Porém, na realidade brasileira, como é perceptível pelos trabalhos elencados, devido acreditamos a aproximação da arquivologia com a ciência da informação, especialmente no ambiente da organização da informação e do conhecimento, têm-se privilegiado discussões que abordam essa temática.

Sem buscar esgotar o tema, que é complexo, busca-se neste artigoensaio fazer uma reflexão a respeito do conceito de representação presente no universo teórico da organização do conhecimento e sua relação com arquivologia. Essa busca visa de forma retrospectiva apresentar por onde caminhamos e vislumbres para o futuro, tendo em mente que a representação assim como a preservação tornaram-se processos ainda mais fundamentais no contexto dos documentos digitais e eletrônicos à medida que é impossível acessá-los sem termos meios de codificá-los e guarda-los, torando os processos representativos ainda mais fundamentais para o cotidiano das organizações.

\section{ORGANIZAÇÃO DO CONHECIMENTO E DA INFORMAÇÃO: EXPLORANDO O CONCEITO DE REPRESENTAÇÃO}

$\mathrm{Na}$ literatura da área de ciência da informação a representação desenvolve-se majoritariamente no que conhecemos como organização da informação, ou seja, a partir dos processos de análise, síntese, condensação, 
representação, e recuperação do conteúdo informacional. Assim representar seria um desses processos com a intenção de facilitar o acesso e a recuperação informacional.

A palavra representação latina, oriunda do vocábulo repraesentare que significa "tornar presente" ou "apresentar de novo". No latim clássico, seu uso é quase inteiramente reservado para objetos inanimados e não tem relação alguma com pessoas representando outras pessoas ou com o Estado romano, quando pensamos em representar, estamos sempre reapresentando, resinificando, revendo, ou seja, o ato evidenciar algo novamente, como um reflexo.

Gostaríamos de nos ater como um ponto de partida para a reflexão buscar um conceito da representação em si, olhado em dicionários de filosofia, na sociologia e na história áreas que também trabalham com o ideário das "representações".

$\mathrm{Na}$ filosofia (ABBAGNANO, 2007, p. 853-854) o contexto aproxima-se bastante da questão de "semelhança" assim "Em primeiro lugar, designa-se com este termo aquilo por meio do qual se conhece algo; nesse sentido, 0 conhecimento é representativo, e representar significa ser aquilo com que se conhece alguma coisa", do ponto de vista filosófico é necessário conhecer o que se está representado, ou seja, é necessário dominar o campo que se representa. Ainda: "Em segundo lugar, por representar entende-se conhecer alguma coisa, após cujo conhecimento conhece-se outra coisa; nesse sentido, a imagem representa aquilo de que é imagem, no ato de lembrar.", ou seja, quando representamos estamos produzindo um reflexo daquilo que é representado, não é a coisa-em-si, mas um fac-símile. "Em terceiro lugar, por representar entendese causar o conhecimento do mesmo modo como o objeto causa 0 conhecimento". Nas três acepções, vê-se a questão do conhecer para representar, o segundo a imagem que se reapresenta e o objeto em si, ou seja, o registro do que se quer representar.

No campo das ciências humanas, as representações sociais são, uma maneira de interpretar e comunicar, mas também de produzir e elaborar conhecimentos, ou seja, são um fac-símile do conhecimento que se relacionam 
em um contexto coletivo. Moscovici conceitua que, "são conjuntos dinâmicos, seu status é o de uma produção de comportamentos e de relações com o meio ambiente, de uma ação que modifica aquelas e estas e não de uma reprodução desses comportamentos ou dessas relações, de uma reação a um dado estímulo exterior". (MOSCOVICl, 1978, p. 50)

As representações sociais objetivam transformar o desconhecido em conhecido, o não familiar em familiar. Tornar o estranho, o perturbador em algo próximo, íntimo, é seu intuito. Esse processo transformador é determinado pelo conhecimento, imagem e o objeto em si, ou seja, é necessária uma materialidade discursiva, ideológica, religiosa, social para que seja representada e compartilhada pela comunidade.

Pode-se pensar, com base no exposto acima, que as representações sociais, enquanto saber partilhado pelo grupo, possibilitam o entendimento da realidade. Ainda que enviesado e que sofra pagamento da ideologia nas representações sociais, atua como uma rede que auxilia na compreensão da comunidade.

Por outro lado, no contexto da literatura da área de organização do conhecimento, acredita-se que a representação enquanto uma atividade, relaciona-se a representar o conhecimento institucionalizado e socialmente referenciado. Assim, nos processos de representação estamos trabalhando com conceitos, ou seja, ideias relevantes de que rementem a um determinado domínio, com bem nos ensina Dahlberg (1978). Complementando esse perceptivo "conhecimento é feito de conceitos [...] e conceitos podem ser ordenados de forma diversa e utilizável" (SMIRAGLIA, tradução nossa, p. 2, 2013). De acordo com Bräscher e Café (2008), a organização do conhecimento diz respeito à organização e à sistematização cognitiva-abstrata do conhecimento, à organização dos conceitos, bem como à construção de sistemas de organização do conhecimento (SOC). Já a organização da informação está voltada à materialidade dos objetos informacionais, ou seja, o conhecimento socializado e institucionalizado.

No contexto da recuperação da informação (RI), existiu uma tendência histórica de relacionar com a recuperação dos documentos Lancaster (1968) irá 
dizer que um sistema de recuperação não recupera a informação, mas apenas informa a existência ou a não de documentos relacionados com a requisição do usuário.

Assim o processo de representação trata-se de um processo de condensação destes conceitos organizados e representado de uma forma que auxiliem quem tem a necessidade e o interesse de utilizá-los. As unidades conceituais funcionam como base para uma efetiva representação, a organização do conhecimento é então como Brasher e Café (2008) estabelecem uma relação conceitual logica própria ao domínio que se está representando. Assim, o conhecimento precisa ser representado por meio de seus conceitos para sua efetiva organização, ou seja, pensar os conceitos auxilia no processo de definição dos instrumentos de representação e sua elaboração e nesse sentido se estabelece uma relação indissociável entre a organização do conhecimento e sua representação.

Hjørland em um texto publicado em 2012 busca comparar por meio de um estudo bibliométrico os conceitos de organização do conhecimento, organização da informação, arquitetura da informação, chegando à conclusão que todos esses campos trabalham com assuntos, conceitos, relações semânticas entre os conceitos. Sendo a base de conhecimento de todos esses termos bastante semelhantes, ainda que exista diferença nas ambiências de aplicação, a arquitetura da informação organizando conceitos e assuntos na web, organização do conhecimento mais vinculada ao universo das bibliotecas e bases de dados bibliográficos, para ele, do ponto de vista da pesquisa as diferenças são mais superficiais e que essenciais.

Assim, a representação documental trata-se de um processo que irá interligar as instâncias do conhecimento por meio dos conceitos com o seu registro informacional.

Descrever o conteúdo documental sua tematicidade, ou seja, seus conceitos, percebe-se então a existência de uma relação fundamental entre organizar a informação e o conhecimento, interacionados e interdependentes.

Essa reflexão, do ponto de vista conceitual, auxilia a demarcar o campo tradicional da discussão acerca da representação documental. 
Se por um lado é difícil, separar a organização da informação da organização do conhecimento e existir um fundamento de que a primeira é complementar ao trabalho desenvolvido na segunda, a mesma problemática irá acontecer quando falando de representação documental, representação do conhecimento e representação da informação.

Vejam, que desde os trabalhos de Dalberg $(1978 ; 1993)$ a unidade básica é o conceito ou seja, o ato de organizar está relacionado a uma sistematização lógica dos termos significativos no contexto de um determinado conceito, por exemplo, o que é o conceito de documento se não os termos utilizados para representa-lo.

Como um exercício vamos apresentar uma relação taxonômica de um conceito:

Figura 1 - Taxonomia de gestão de documentos

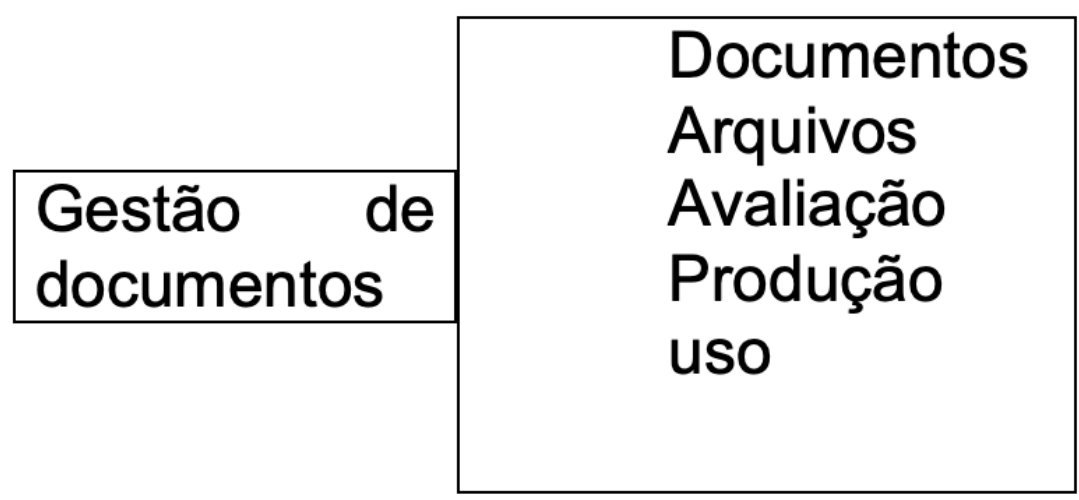

Fonte: Elaborado pelo autor (2020)

O conceito de gestão de documentos está relacionado aos termos selecionado para representá-lo. Assim a separação entre representação do conhecimento/informação está muito mais relacionada a passagem do campo dos conceitos (conhecimento) para campo da materialidade (informação).

Assim a representação documental, do ponto de vista desta linha de raciocínio está relaciona a um processo de representar o conhecimento e organizar a informação contida em documentos.

Quando pensamos então, na representação no contexto da arquivologia, estamos falando de uma forma arquivística de representar o documento, numa 
relação entre o conhecimento produzido pelas instituições e a produção de informação em documentos jurídicos administrativos que comprovam, informam, auxiliam e fundamentam ações institucionais.

Portanto, representar no contexto arquivísticos significa compreender que o documento arquivísticos está nessa relação entre conhecimento-informação e sua organização.

\section{REPRESENTAÇÃO DOCUMENTAL ARQUIVÍSTICA: TRAJETÓRIA DE UM CONCEITO}

A representação no contexto da arquivologia está relacionada ao cotidiano organizacional das instituições públicas e privadas no contexto dos papéis exercidos e os documentos produzidos. Assim os sistemas de representação arquivística devem lidar com essa realidade e sistematizar e reapresentar essa produção cotidiana de documentos (YAKEL, 2003).

O processo de classificação e descrição do material arquivístico, trata-se de algumas das funções mais importantes do trabalho do arquivista. São trabalhos fundamentais na miríade de documentos produzidos, recebidos e/ou doados pelas instituições. Sem os processos de representação é impossível qualquer nível de uso dos documentos produzidos, influenciando no processo de gestão, acesso, uso e avaliação documental.

Assim, o documento arquivístico trata-se de um objeto físico/digital com uma compreensão ou representação. Algumas das coisas o torna importante estão no documento-em-si, mas o que faz com que ele seja compreensível não está. (NESMITH, 1999)

Portanto, a representação no contexto arquivístico deve lidar com a representação do documento, mas também com a representação do contexto, ou seja, as representações institucionais, sociais e culturais, nesse cenário que surge o conceito de societal provannace. Todos os documentos têm uma proveniência social, não apenas documentos interculturais, mas todas as camadas da proveniência da informação têm fontes sociais. "A proveniência social não é só outra camada de descrição informacional, como o nome do criador, as funções ou ligações estruturais ou organizacionais. A proveniência 
social está infusa em todas elas" (NESMITH, tradução nossa, 2006, p. 352).

O conceito chave para representação na arquivística é o da proveniência, que acordo com o Conselho Internacional de Arquivos (CIA) (2007) pode ser definida como: O relacionamento entre e os documentos e as organizações ou indivíduos que os criaram, acumulados ou mantidos e usados na condução de ações corporativas ou pessoais. A proveniência também está relacionada as ligações entre as funções que consequentemente levam a produção de documentos em um contexto institucional particular.

Portanto, do ponto de vista da representação é necessário relacionar as funções institucionais/sociais (classificação) e apresentá-las em detalhes (descrição), o processo de representação é indissociável dessas duas facetas da representação do conhecimento arquivístico.

Se no contexto da representação e organização do conhecimento representar a informação se parte de unidades conceituais de um determinado domínio, no condicionante arquivístico, isso também é verdade, porém esse domínio e suas unidades conceituais, não são só por unidades epistemológicas disciplinadas pela ciência-cultura, é atravessada pela burocracia institucionalizada em aparelhos do Estado.

Quando classificamos, a proveniência é responsável pela primeira pista para rastrearmos as origens contextuais, identificando as funções, atividades e decompondo a estrutura do órgão a fim de representá-la. Na descrição a complexidade dessa proveniência social fica mais evidente, à medida que afeta todo o processo de representação, no contexto digital isso é ainda mais importante, devido as necessidades de sistemas de busca, sistemas de produção/gestão de documentos em ambientes digitais e o reuso e maior dispersão dos acervos e também, a perda do vínculo custodial o caráter probatório do documento arquivístico. Assim, do ponto de vista do traço contextual, pensar a proveniência é a premissa básica para a representação documental na arquivologia.

A proveniência também tem um papel importante quando pensamos o uso e acesso aos documentos, a busca, majoritariamente parte de quem produziu aquele conjunto documental e como os documentos se relacionam. Assim, o 
impacto da proveniência na forma das representações descritivas tem uma importância fundamental.

Do ponto de vista de identificação da providência documental, é feito de forma normalmente manual e de várias fontes, ou seja, ainda quem existam sistemas automatizados para o trabalho descritivo, como o Atom (Acess to memory do CIA) por exemplo, ou normas de descrição, ou normativas ISO (ISO 15489/ 30300) que tratam-se dispositivos para a gestão documental, que também apresentam requisitos para a classificação arquivística. Todo trabalho intelectual demandado é tradicionalmente feito de forma manual, o que dificulta o processo e acreditamos, que essa seja uma das coisas mais importantes na conjuntura atual, elaboração de softwares que auxiliem a automação.

Os caminhos para essa representação, podem ser enumerados da seguinte forma: 1) Estudo da estrutura administrativa dos órgãos produtores/custodiares ou biografias de indivíduos (tanto para arquivos institucionais quanto pessoais); 2) Agentes públicos e/ou privados que poderão servir como testemunhas a história administrativa/privada (usuários, gestores, produtores, familiares, etc.). 3) Análise das funções e das atividades do órgão produtor 4) Definição de políticas de representação para a entidade custodiadora por fim, 5) Construção de instrumentos de pesquisa, planos de classificação para auxiliar na construção da história contextual e auxiliarem os gestores e usuários na recuperação e acesso a essas informações.

Esse processo passo a passo irá auxiliar no desenvolvimento dos instrumentos que compreendemos como ser de representação.

Com base em Yakel (2003, p. 2, tradução nossa) "A representação arquivística é como uma prática construída socialmente de forma fluida e evolutiva. A representação refere-se aos processos de classificação [...] e descrição para a criação de ferramentas de pesquisa [...]. ou sistemas [...]."

Os processos de representação documental arquivísticos tem uma forte relação com a classificação e a descrição e ainda na elaboração de sistemas de recuperação da informação. Portanto a relação fundamental no binômio informação-conhecimento está presente ainda que a trajetória seja distinta. 


\section{CLASSIFICAÇÃO E DESCRIÇÃO ARQUIVÍSTICA: A REPRESENTAÇÃO DOCUMENTAL NO CONTEXTO DA ARQUIVOLOGIA}

As representações são os processos de classificação e descrição ao redor de limites pré-estabelecidos pela interpretação do arquivista em relação ao conhecimento produzido e registrado no contexto organizacional, dado essa premissa e nosso relato anterior, ainda que existam princípios e relacionamentos entre eles e os documentos produzidos no contexto institucional, ainda permanece uma dificuldade enorme nos seu uso, dado os filtros e narrativas que são construídas a partir dessas representações que carregam uma certa ambiguidade, ou melhor, carregam a representando subjetiva de quem a produz. Aliás, essa é uma realidade na representação documental, existirá em maior o menor grau a ambiguidade e incompletude de quem as produziu.

Yekel (2003) irá estabelecer três níveis de nichos/desenvolvimentos de representação, a primeira é aquela criada por quem produz o documento, o que na arquivologia chamamos de ordem (ou desordem) original, ou seja, trata-se de um primeiro filtro do processo de representação. Secundariamente, estamos falando dos arquivistas em si mesmos que irão em seus processos de representação abordados na seção anterior buscar melhor representar os domínios das instituições sub sua custodia e por fim de potencializar o acesso e a preservação, por fim, os sistemas responsáveis por agrupar as várias representações e bancos de dados e ferramentas de busca, que novamente irão representar esses documentos, além dos próprios instrumentos, no caso, os planos de classificação, politicas, descrições, pontos de acesso, etc.

Portanto, invariavelmente, sempre existirá uma filtragem e um grau de ambiguidade na representação, o que é necessário neste processo é considerar que o filtro existe.

Dito isso, do ponto de vista programático, a classificação desenha os processos de gestão, de organização e de representação dos documentos de arquivo, esses sistemas de representação irão possibilitar o desenvolvimento de todos os outros procedimentos organizacionais, ou seja, a classificação é uma atividade crítica que precisa fomentar os processos posteriores. 
O sistema além de hierárquico é profundamente estruturado, porém carece de rigor formal, normalização e de inter-relacionamentos, o que provoca problemas de navegação, uso e compreensão por parte da comunidade que os utiliza.

$\mathrm{Na}$ arquivologia, sempre temos em mente dois usuários ideais, e para eles buscamos construir nossos instrumentos, primeiramente aquele que produz os documentos, em muitos casos seu maior interessado ao longo da cadeia de custódia, buscando respostas a problemas jurídicos e administrativos com a sua consulta e que comumente classifica os documentos tendo por base um código previamente elaborado (o primeiro nível de representação que destacamos anteriormente), sua falta de participação no desenvolvimento da categorização ou mesmo de ver sua cultura organizacional representada no código faz com que exista uma dificuldade de utilizar e buscar nesse código, ou seja, a premissa de Dahlberg e dos SOC's tradicionais auxilia neste processo, ou seja, de compreender as unidades documentais como parte do processo indissociável de informação-conhecimento.

Já o outro lado da moeda é o que apresenta ainda mais dificuldade de utilizar instrumentos de representação típicos de arquivo, porque neste caso várias camadas de representação já foram geradas, por quem produz, por quem organiza e por fim por quem recupera. É necessário primeiramente compreender a lógica de organização, ou seja, como a instituição produziu os documentos e como a equipe/arquivista construiu para depois finalmente fazer sua pesquisa, um processo profundamente calcado numa visão dos documentos buscados presencialmente e da organização física.

Yekel (2003) narra um fato interessante considerando essas várias mudanças nas representações, falando de um arquivo pessoa de Colin Mackenzie, cartógrafo da East Indian Company na India, que colecionou um vasto conjunto documental durante sua atuação, os documentos primeiramente foram organizados pelo próprio titular, estabelecendo uma lógica própria de representação passiva e ainda sim influenciando a coleção, mas tarde o arquivo foi transferido e representando como documentos colacionais, mais tarde como documentos em no contexto histórico do império britânico, por fim, historiadores 
tentando reestabelecer a ordem original dos documentos buscando estudar melhor o contexto de produção documental. Esse fato narrado pela autora, conta uma história comum na ambiência dos arquivos, essa constante ressignificação e reinterpretação não só dos códigos, mas dos documentos em si, ou seja, as representações e narrativa decorrente dela se modifica a medida que as comunidades e instituições utilizam o documento de forma diversas do motivo pelo qual os documentos foram orginalmente produzidos.

Uma noção muito próxima daquela que apresentamos anteriormente como proveniência social, mas relacionada as relações intrínsecas, é a noção de Duranti (1997) irá chamar de archival bond, ou seja, os documentos só fazem sentido relacionando uns aos outros, na medida em que um processo de contratação de pessoal, só conta sua história administrativa, com todos os seus documentos.

Isso é de fácil percepção nos documentos produzidos analogicamente, mas não é tão explícito em ambiente digital, ou seja, é necessário que isso fique evidente na categorização da classificação, especialmente no contexto digital. Assim, a "temática" do documento, não se relaciona apenas a uma única categoria de assunto, como no caso exemplificado, mas a relação entre esse processo, outros processos da mesma atividade e o negócio institucional. Ele conta a história administrativa no relacionamento, um ofício sem si mesmo não evidencia o motivo pela sua criação, mas sim os documentos que são anexados a ele que comprovam e corroboram a tomada de decisão.

Isso comprova a complexidade do processo de classificação contextual na arquivologia, ao ponto de em muitos casos um código que se estabelece como puramente funcional, na prática mescla contexto e assuntos em sua categorização, dificultando sua aplicação.

Por exemplo, um uma carteira de identidade comprova quem é aquela pessoa e suas filiações, ou seja, é um documento que informa sobre o titular. Do ponto de vista da classificação contextual essa é sua função ou seu conteúdo? A linha não é tão clara quanto parece. Portanto, quando pensamos nisso, podemos dizer que sim, entendemos, que existe uma característica fundamental a classificação/descrição arquivísticas, relacionada a proveniência/organicidade 
documental que são os fundamentos para a organização dos registros orgânicos. No entanto, a maneira como o fazemos é conceitual e semântica, mas carecemos de ferramentas e estudos para reconhecer isso ou mesmo uma discussão aprofundada sobre as relações semânticas nos instrumentos de representação da arquivologia.

Assim o processo de representação documental no contexto da arquivologia, pode ser completado com aquele que descrevemos em relação a organização do conhecimento. (BARROS; SOUSA, 2019 a ou b ; BARROS; GOMES, 2018)

Em relação ao processo, Foscarini (2006, p. 41) estabeleceu que poderíamos defini-lo como uma investigação preliminar, seguida da análise funcional top-down e da análise dos processos combinados bottom-up. A classificação funcional se deve à padronização administrativa e ao desenvolvimento da burocracia desde o final da Segunda Guerra Mundial, levando à racionalização e, ao mesmo tempo, a um aumento exponencial da complexidade de produção e uso de documentos jurídico-administrativos.

Ter a proveniência como premissa do sistema e a análise funcional como elemento constituinte do sistema de representação o frame geral do sistema de classificação, porém a execução real do sistema em seu passo a passo pode ser complementada por um outro SOCs, porque sim, o esquema classificatório doa arquivos também é um SOC especializado.

A organização do conhecimento e os SOCs tradicionais podem auxiliar no desenvolvimento de classificações, que acreditamos seja a fase crucial do processo para a aplicação ainda que seja possível aplicá-las posteriormente na descrição arquivística (vocabulários controlados, taxonomias, etc.), ou seja, na faze mais descritiva e ampla do processo de representação, onde corre com mais clareza processo de análise documental, construção de resumos, descrição física dos acervos.

Esse processo busca auxiliar a diminuição da subjetividade, navegação e uso desses SOC como vemos em Sousa e Araújo Junior (2013; 2017) quando abordam as taxonomias, e em Barros e Gomes (2018) e Gomes et al. (2020) ao abordar as ontologias. 
Um fator crítico que torna possível aplicar um SOC no contexto de arquivos públicos é que a maioria das atividades organizacionais são repetitivas; são instâncias de processos executados com frequência. Então, é aqui que a unidade conceitual de Dahlberg pode nos ajudar a delinear como nomeamos ou mesmo definimos os conceitos, com base nas relações entre termos e conceitos em um determinado domínio jurídico-administrativo, pode ajudar a construir melhores instrumentos.

Alguns autores apontam o problema que ocorre em relação não apenas à classificação, mas é um problema recorrente na arquivística que pode ser auxiliado pela teoria dos conceitos e pelo desenvolvimento do SOCs: a nomeação de classes em ferramentas de pesquisa e esquemas de classificação. Orr (2005, p. 111) estabeleceu que "Não existe um modelo comum de classificação baseado em regras, seja no número de elementos, seja nos níveis ou na nomenclatura das classes." Outro problema recorrente é a falta de aprofundamento de teorias sobre as metodologias do campo; de acordo com Hurley (1993, tradução nossa, p. 11), "A ciência e a metodologia da análise funcional ainda não foram escritas." Desde meados da década de 1980, os estudos têm se concentrado em questões conceituais, mas com poucas reflexões fundamentalmente metodológicas. Shepherd e Yeo (2003, p. 73) escrevem que "Os esquemas de classificação são baseados em uma análise de funções, processos e atividades". No entanto, quando olhamos para o sistema de classificação de si, como afirma Foscarini (2006, p. 191), "o número de sistemas de classificação que afirmam ser baseados em funções, em um olhar mais profundo acaba sendo apenas um espelho da estrutura interna da agência (estrutura)", não refletindo as funções de negócios.

O que argumentamos aqui é que podemos construir um processo, um fluxo de atividades que ajuda a desenvolver melhores esquemas de classificação. Os arquivos não são construídos por acaso, a história é feita dia a dia com documentos do cotidiano, as informações contidas nestes documentos evidenciarão visões da sociedade, de fatos, de comportamentos e de períodos de todas as épocas, são por si só representações sociais do cotidiano de comunidades. 
Documentos são produtos das ações desenvolvidas em uma instituição, ou por uma pessoa, são criados para auxiliar as atividades e prestar testemunho de uma época, um período ou uma gestão. Os documentos são únicos e seus conteúdos adquirem sentido pleno se tiver uma relação com o restante dos documentos que foram criados. Os documentos são gerados em função das atividades administrativas e jurídicas de uma instituição e agrupados em séries, subséries, seções e fundos documentais.

Desta maneira, para a Organização do Conhecimento nos arquivos a atividade de classificação desempenha um papel essencial na gestão documental, ao ser realizada e calcada nos estudos das legislações, dos procedimentos, das funções da instituição e ainda conta com a participação do usuário na medida em que este como gerador da informação auxilia no processo de contextualização do arquivo, para que, seja elaborado esquemas de classificação que atenda e represente o universo daquele acervo. Aos termos uma visão mais clara do contexto em que os arquivos foram produzidos é possível ter uma melhor representação da informação facilitando o acesso e a recuperação da mesma.

O sucesso e o desenvolvimento das instituições está cada vez mais relacionado com a sua capacidade de criar, disseminar, compartilhar e utilizar conhecimento. A gestão documental auxilia na recuperação da informação pelo usuário. Portanto, os sistemas de OC neste sentido são mecanismos pensados para representar e recuperar a informação com o acesso aos registros de arquivo, por meio de esquemas que representam e organizam as informações como: ontologias, taxonomias, tesauros, planos de classificação, vocabulários controlado, ou seja, os instrumentos que organizam e representam a informação a partir de desenhos conceituais.

A Arquivologia e os SOCs estão diante de uma oportunidade única com desafios pela frente, as pesquisas pelas informações e a geração de novos conhecimentos nunca foram tão intensas e rápidas como nos dias de hoje.

Os instrumentos de classificação aliados à tecnologia, aos usuários, que utilizam a web para realizar pesquisas que estão cada vez mais exigentes e querem informação de maneira mais ágil e precisa, forçam os profissionais de 
arquivo e as instituições a encarar a questão da classificação nos arquivos seja realizada na geração do documento, facilitando assim a recuperação da informação.

Os Sistemas de Organização do Conhecimento dão suporte a gestão no momento em que os esquemas de classificações/descrições refletem e representam as características e especificidades de cada instituição tendo como base o contexto arquivístico para melhor representar a informação e a organização.

Assim, do ponto de vista da aplicação, a primeira coisa é construir uma política que estabeleça uma base para todo o processo, o trabalho intelectual desenvolvido pelos arquivistas para projetar 0 esquema de classificação/descrição, ou seja uma política de representação documental arquivística.

Então construir uma relação de termos-conceitos com um SOC (uma taxonomia por exemplo) do domínio institucional com base na conexão entre conceitos, termos e usuários em um processo top-down, bottom-up, para então, com este estudo de referência cruzar a construção real da classificação com suas notações relacionando conceitos, em sua ideia triangular de Dahlberg e os termos que eles representam no domínio institucional.

Com esta descrição parece que o trabalho é fácil, mas não é; é um processo complexo que, desta forma, tem uma abordagem mais equilibrada do que a tradicional. Fizemos isso em alguns artigos teórico-metodológicos como Barros e Gomes (2018) e Gomes et al. (2020), fizemos protótipos e o processo funcionou. Desejamos construir sistemas melhores e esta é uma forma possível de fazê-lo.

\section{CONCLUSÕES}

Buscamos ao longo deste texto apresentar uma sistematização e por meio de um percurso conceitual ao redor do conceito de representação, abordamos primeiramente do ponto de vista filosófico e histórico, para depois desenvolvê-lo a partir da literatura de organização do conhecimento, por fim apresentamos a discussão e relações possíveis no contexto da arquivologia, primeiro com base 
nos princípios depois em relação as funções. Acreditamos que os processos de representação em uma discussão normalizadora seja fundamental para avanços nos procedimentos representativos da arquivologia esse processo tem que vir acompanhando de uma discussão sobre as relações semânticas estabelecidas nesses instrumentos como podemos tornas menos subjetivas e individualizadas, ou seja, essa reflexão buscando reduzir a ambiguidade presente na representação, o que acreditamos ser na verdade, uma agenda de pesquisa tão importante para a arquivologia, como para representação documental e organização do conhecimento. fundamental para a arquivologia no sentido de que auxilia os profissionais.

Acreditamos que, a relação da arquivologia cada vez maior com a OC na prática irá auxiliar a sanar um dos maiores entraves encontrados nos arquivos, a classificação e o tratamento documental na gestão documental, pois a atividade deverá estar voltada para atingir o real objetivo da mesma: atender as funções das instituições e as pesquisas dos usuários e desta forma conseguir representar o contexto arquivístico e recuperar a informação de maneira útil e satisfatória para o usuário.

De acordo com Barros e Sousa (2019 a ou b) a organização e representação do conhecimento é uma área que contribui de forma fundamental para o desenvolvimento de metodologias para o acesso à informação, desta forma a aproximação da arquivologia no contexto da representação do conhecimento contribui muito para construção de metodologias para organização e acesso nos mais variados tipos de acervos nos mais diferentes contextos auxiliando na replicação e adaptabilidade dos instrumentos por ela desenvolvidos. É importante sinalizar, que mais do que uma crítica aos fundamentos da área, busca-se um prolongamento e uma complementação a trabalhos já realizados.

Os desafios para arquivistas em relação à representação sempre estiveram presentes, justamente, por ser muito provavelmente o processo mais difícil de se desenvolver na organização arquivística. O percurso aqui relatado de forma sistematizada compreendemos que estamos falando de uma disciplina aplicada, ou seja, que o desenvolvimento teórico deve acompanhar o 
desenvolvimento metodológico.

Nossa trajetória de pesquisa tem sido nos últimos anos buscar meios e construir caminhos para essas respostas por meio de projetos de pesquisa, pesquisas de iniciação cientifica graduação e orientações de pós-graduação que buscam por intermédio da relação entre representação e organização do conhecimento e da informação respostas ainda que preliminares sobre os possíveis avanços aplicados e alguns protótipos que já foram criados e apresentados, nosso próximo passo a partir da reflexão aqui apresentada será buscar analisar as estruturas semânticas nos instrumentos de representação afim de identificar com tem sido construída categorização e como podemos aprimorá-la, independentemente de críticas eventuais a trajetória conceitual da área, nossa preocupação permanece a mesma aprimorar nossos processos para melhor atender a sociedade.

\section{REFERÊNCIAS}

ABBAGNANO, N. Dicionário de Filosofia. São Paulo: Martins, Fontes, 2000.

ALENCAR, M. F.; CERVANTES, B. M. N. Organização e representação do conhecimento arquivístico: em busca de um método para construção de tesauro funcional. Em questão, Porto Alegre, v. 25, n. 1, p. 368-389, 2019 a.

ALENCAR, M. F.; CERVANTES, B. M. N. Acesso à informação arquivística: uma aproximação teórica da vertente pós-custodial com o tesauro funcional. Informacao \& Sociedade-Estudos, v. 29, n. 2, p. 85-100, 2019b.

ASSOCIAÇÃO BRASILEIRA DE NORMAS TECNICAS. ISO 15489-1:2018 Informação e documentação - Gestão de documentos de arquivo. Parte 1: Conceitos e princípios. São Paulo. 2018.

ASSOCIAÇÃO BRASILEIRA DE NORMAS TECNICAS ISO 30300:2016 Informação e documentação - Sistema de gestão de documentos de arquivo Fundamentos e vocabulário. São Paulo. 2016.

BARROS, T. H. B. A Indexação e a Arquivística: aproximações iniciais no universo teórico da organização e representação do conhecimento. Encontros Bibli (UFSC), v. 21, p. 33, 2016.

BARROS, T. H. B.; GOMES. D. L. Classification, Knowledge Organization Systems: ontologies and archival classification. In: INTERNATIONAL ISKO CONFERENCE, 15, Anais [...], Porto, Portugal, 2018. 
BARROS, T. H. B.; SOUSA. R. T. B. Archival Science and Knowledge Organization: Mapping Methodological Relationships. Knowledge Organization v. 46, n. 7, p. 493-501, 2019 a.

BARROS, T. H. B.; SOUSA. R. T. B. Organização do conhecimento e arquivologia: abordagens metodológicas. Informação \& Informação, v. 24, n. 2, p. 76-92, 2019b.

BARROS, T. H. B.; MORAES, J. B. E. de. Da classificação biológica à classificação digital: perspectivas de renovação em classificação arquivística. Revista Ágora, Florianópolis, v. 23, n. 46, p. 58-84, jun. 2013

BARROS, T. H. B.; MORAES, J. B. E. Archival Classification and Knowledge Organization: Theoretical Possibilities for the Archival Field. In: NEELAMEGHAN, A.; RAGHAVAN, K.S (Orgs). Categories, Contexts And Relations In Knowledge Organization. Proceedings of the Twelfth International ISKO Conference 6-9 August 2012 Mysore, India. Wurzburg: Ergon-verlag Gmbh, v. 13, p. 272-276, 2012.

BRASCHER, M.; CAFE, L. Organização da informação ou organização do conhecimento? In: ENCONTRO NACIONAL DE PESQUISA EM CIÊNCIA DA INFORMAÇÃO, 9., 2008, São Paulo. Anais [...], São Paulo: USP, 2008

CONSELHO INTERNACIONAL DE ARQUIVOS. Norma internacional para descrição de funções Conselho Internacional de Arquivos: Paris, 2007.

DAHLBERG, I. A Referent-Oriented, Analytical Concept Theory for INTERCONCEPT. International Classification, v. 5, n. 3, p. 142-151, 1978.

DAHLBERG, I. Knowledge Organization: Its Scope and Possibilities. Knowledge Organization, v. 20, n. 4, p. 211-233, 1993.

DURANTI, L. The Archival Bond. Archives and Museum Informatics, v. 11, p. 213-218, 1997.

FOSCARINI, F. Records classification and functions: an archival perspective. Knowledge Organization. v. 33, n. 4, p. 188-198, 2006.

GOMES. D. L.; BARROS, T. H. B.; SOUSA, R. T. B.; SANTOS JUNIOR, R. L. Proposta de uma Ferramenta para Classificação Arquivística com Base em Ontologias. Em Questão, Porto Alegre, v. 26, n. 1, p. 351-374, 2020.

GUIMARÃES, J. A. C.; TOGNOLI, N. B. Provenance as a Domain Analysis Approach in Archival Knowledge Organization. Knowledge Organization, v. 42, n. 8, p. 562-69, 2015.

HENTTONEN, P. Dimensions of Contextual Records Management Classifications. Knowledge Organization, v. 42, n. 4, p. 477-485, 2015. 
HENTTONEN, P. Diversity of Knowledge Organization in Records and Archives Management. In: Neelameghan, A. and Raghavan, K. S. (Eds.). (2012).

Categories, contexts and relations in knowledge organization: Proceedings of the Twelfth International ISKO Conference (Mysore, India, August 6-9, 2012). Advances in knowledge organization, no. 13. Würzburg: Ergon.

HENTTONEN, P.; KETTUNEN, K. Functional classification of records and organisational structure. Records Management Journal, v. 21, n. 2, p.86-103, 2011.

HURLEY, C. What, if anything, is a function? Archives and Manuscripts, v. 21, n. 2, p. 208-220, 1993.

HJØRLAND, B. Knowledge Organization = Information Organization? In: NEELAMEGHAN, A.; RAGHAVAN, K. S (Eds.). International ISKO Conference, 20, Anais [...]. Mysore, India: Ergon Verlag, 2012. p. 8-14.

LANCASTER, F. W. On the need for role indicators in postcoordinate retrieval systems. American Documentation, v. 19, n. 1, p. 42-46, 1968.

MOSCOVICI, S. A representação social da psicanálise. Rio de Janeiro: Zahar Editores, 1978.

NESMITH, T. Still Fuzzy, But More Accurate: Some Thoughts on the 'Ghosts' of Archival Theory, Archivaria, v. 47, p.144-160, 1999.

NESMITH, T. The Concept of Societal Provenance and Records of NineteenthCentury Aboriginal-European Relations in Western Canada: Implications for Archival Theory and Practic. Archival Science, v. 6, p.351-360, 2006.

ORR, S. A. Functional-based classification of records: is it functional? 2005, $170 \mathrm{f}$. Thesis (Mestrado) - Master of Science in Records Management Course, Northumbria University, Newclaste, 2005.

PACKALÉN, S.; HENTTONEN, P. Ambiguous Labels: Facet Analysis of Class Names in Finnish Public-Sector Functional Classification Systems. Knowledge Organization, v. 43, n. 7, p.490-501, 2016.

SHEPHERD, E.; YEO, G. Managing records: a handbook of principles and practice. London: Facet, 2003.

SOUSA, R. T. B; ARAÚJO JÚNIOR, R. H. de. A classificação e a taxonomia como instrumentos efetivos para a recuperação da informação arquivística. Ciência da Informação: Brasília, v. 42, n. 1, p. 131-144, jan./abr., 2013.

SOUSA, R. T. B.; ARAÚJO JÚNIOR, R. H. de. A indexação e criação de taxonomias para documentos de arquivo: proposta para a expansão do acesso e integração das fontes de informação. Brazilian Journal of Information Science: Research Trends, v. 11, n. 4, p. 47-56, 2017. 
SMIRAGLIA, R. P. The Epistemological Dimension of Knowledge Organization. IRIS-Re N. Bolfarini Tognoli, A. C. Rodrigues, and J. A. Chaves Guimarães. Archival Knowledgevista de Informação, Memória e Tecnologia, v. 2, n. 1, p. 2-11, 2013

TOGNOLI, N. T.; RODRIGUES, A. C.; Guimarães, J. A. C. Archival Knowledge Conceptual Frameworks for Recent Terminology in the KO Domain Knowledge Organization v. 46, n. 7, p. 523-529,2019

YAKEL, E. Archival representation. Archival Science, n.3, p.1-25, 2003.

YAKEL, E. Who represents the past? Archives, records and social web. In: COOK, T. (Ed.). Controling the past: documenting society and institutions. Chicago: Society of American Archivists, p.257- 78, 2011.

\title{
ARCHIVAL REPRESENTATION: RECENT PERSPECTIVES
}

\begin{abstract}
Introduction: Representation processes are part of the daily life of archives, libraries and museums. In this sense, it is sought in the universe of archives to appropriate the discussions related to the representation and knowledge organization and information Objectives: This article discusses the path of the concept of representation first in the context of the organization then in the context of archival science with the intention of systematizing the various facets of the concept of representation and bringing them closer to archival processes. Methodology: The work was developed analyzing the literature of both areas around the concept of representation. Results: As it is a theoretical study that discusses and systematizes the literature of the area, it is clear the presence of a concept of representation in archival science although configured in a reality different from the idea present in the Knowledge Organization. Conclusions: In the sense of seeking to work with the convergences between these fields and to present relationship possibilities, improving the construction of representation instruments in the context of the archives today.
\end{abstract}

Descriptors: Representation. Archival Science. Knowledge Organization.

\section{LA REPRESENTACIÓN DOCUMENTAL EN EL CONTEXTO DE LA ARCHIVOLOGÍA: PERSPECTIVAS RECIENTES}

\begin{abstract}
RESUMEN
Introducción: Los procesos de representación forman parte del día a día de archivos, bibliotecas y museos. En este sentido, se busca en el universo de los archivos apropiarse de las discusiones relacionadas con la representación y organización de la información y el conocimiento. Objetivos: Este artículo discute el recorrido del concepto de representación primero en el contexto de la organización y luego en el contexto de la
\end{abstract}


archivología, con la intención de sistematizar las diversas facetas del concepto de representación y acercarlas a los procesos archivísticos. Metodología: El trabajo se desarrolló analizando la literatura de ambas áreas en torno al concepto de representación. Resultados: Al tratarse de un estudio teórico que discute y sistematiza la literatura del área, se evidencia la presencia de un concepto de representación en la archivología, aunque configurado en una realidad diferente a la idea presente en la Organización del Conocimiento. Conclusiones: En el sentido de buscar trabajar con las convergencias entre estos campos y presentar posibilidades de relación, mejorando la construcción de instrumentos de representación en el contexto de los archivos de hoy.

Descriptores: Representación. Archivologia. Organizacion del conocimiento.

Recebido em: $15 / 09 / 2020$

Aceito em: 30/09/2020 